\title{
A Chinese Case of Coronavirus Disease 2019 (COVID-19) Did Not Show Infectivity During the Incubation Period: Based on an Epidemiological Survey
}

\author{
Jong-Myon Bae \\ Department of Preventive Medicine, Jeju National University College of Medicine, Jeju, Korea
}

Controversy remains over whether the coronavirus disease 2019 (COVID-19) virus may have infectivity during the incubation period before the onset of symptoms. The author had the opportunity to examine the infectivity of COVID-19 during the incubation period by conducting an epidemiological survey on a confirmed patient who had visited Jeju Island during the incubation period. The epidemiological findings support the claim that the COVID-19 virus does not have infectivity during the incubation period.

Key words: COVID-19, Coronavirus, Infectious disease incubation period, Epidemiology

The World Health Organization declared the outbreak of novel coronavirus 2019 (2019-nCoV) on January 30, 2020 [1]. With the arrival of Chinese tourists and the domestic travel in conjunction with Chinese New Year's Day and Korean New Year's Day holidays, 24 cases were confirmed in Korea on February 8,2020 . As Jeju Island is a popular tourist destination, the risk of influx of coronavirus disease 2019 (COVID-19) and community spread is higher than any other region in Korea.

Furthermore, there is still controversy over whether the virus is infectious during the incubation period before the onset of symptoms. Chinese authorities reported on January 26, 2020 that COVID-19 is infectious during the incubation period [2]. In addition, a news story from January 28, 2020 [3] and a research paper published on January 30, 2020 [4] reported that a con-

Received: February 17, 2020 Accepted: February 27, 2020

Corresponding author: Jong-Myon Bae, MD, PhD

Department of Preventive Medicine, Jeju National University College of Medicine, 102 Jejudaehak-ro, Jeju 63423, Korea

E-mail: jmbae@jejunu.ac.kr

This is an Open Access article distributed under the terms of the Creative Commons Attribution Non-Commercial License (https://creativecommons.org/licenses/by$\mathrm{nc} / 4.0 /$ ) which permits unrestricted non-commercial use, distribution, and reproduction in any medium, provided the original work is properly cited. firmed patient in Germany had contact with an asymptomatic woman from China two days before the onset of symptoms. There seem to be evidences supporting infectivity during incubation.

If COVID-19 does have infectivity during the incubation period, it is a serious concern because it effectively neuters the current communicable disease control system. Because the starting time of infectivity in a confirmed case has not yet been defined. Fortunately, the author had the opportunity to observe the infectivity of COVID-19 during the incubation period through conducting an epidemiological survey on a confirmed patient who had visited Jeju Island during the incubation period.

A 51-year-old Chinese woman, who lives in Wuhan, China, visited Jeju Island with her daughter through Yangzhou, China on January 21, 2020. They toured Jeju Island from the 22nd to the 24th and returned to Yangzhou on the 25th. The woman's fever started on the 26th, the day after returning home, and she was diagnosed on the 30th. The confirmation of infection was informally communicated to the Jeju Provincial Office on February 1, 2020 afternoon via fax from the airline on which she had traveled.

Due to the confirmed diagnosis in China and the onset of 
symptoms after returning home, she was not subject to epidemiological investigations based on the guideline of the Centers for Disease Control and Prevention in Korea (KCDC). However, on the basis of the German case [3,4], Jeju Provincial Government decided to seek subjects who had face-to-face conversations with the patient on the 24th and 25th, two days before the day of symptom onset, and to take measures to quarantine up to 14 days of maximal incubation period.

By using social networking service with the patient's daughter in China and checking the closed circuit television (CCTV) images installed in the hotel and throughout Jeju Island, the patient's travel route and persons with whom she came into close contact were confirmed [5]. Based on these, the author identified eleven persons who had talked directly with the patient for longer than 10 seconds and recommended quarantine to them. None of them showed any symptoms of COVID-19 infection through midnight, February 8, 2020, when the last contact was released from quarantine.

During the quarantine period, it was suggested on February 3, 2020, that the Chinese woman who had contact with the first German patient had already developed symptoms and had been taking antipyretic analgesics during her stay in Germany [6]. This information was contrary to the claim that COVID-19 has infectivity during the incubation period. Additionally, according to the testimony of the doctor in Korea, most of the clinical progress is mild and the patient's condition is stable [7]. It is possible that if the onset of expression is not sudden and starts slowly, the manifestation date pointed to by the patient may be later than in actuality [8]. In light of this, it is possible to explain the confusing claims made by the Chinese authorities [2]. Accordingly, it would be reasonable to conduct an epidemiological investigation one day before the onset of confirmed patients in the 5th edition of the KCDC, which is effective beginning February 7, 2020 [9].

Conversely, if the symptoms are mild, the actual onset of the Chinese case may be earlier than January 26, 2020. However, the author concluded that her symptoms did not manifest during her stay in Jeju Island from the following facts. First, the third-parties such as hotel front desk staff, tour guides, and pharmacists, who had face-to-face contact with the patient, stated that she exhibited no ill symptoms such as dry coughing. Second, in the CCTV video, she walked for a long time and appeared to be a healthy tourist without any disease. These epidemiological findings support the claim that there is no infectivity during the incubation period. However, uncertainty about the possibilities of transmission of latent infection or asymptomatic patients remain, because the epidemiological spectrum of COVID-19 has yet to be accurately identified.

\section{Ethics Statement}

This paper is a perspective so it did not need ethical consideration.

\section{CONFLICT OF INTEREST}

The author has no conflicts of interest associated with the material presented in this paper.

\section{FUNDING}

None.

\section{ACKNOWLEDGEMENTS}

The author thanks Dr. Sung-Huk Lee, Don Haeng Yang, Mi Ya Kim, and Dae Soon Kim at the Bureau of Health-Welfare-Women and Jeju Center for Infection Control and Prevention for their contributions in this submission of an earlier version of the manuscript.

\section{AUTHOR CONTRIBUTIONS}

All work was done by JMB.

\section{ORCID}

$$
\text { Jong-Myon Bae https://orcid.org/0000-0003-3080-7852 }
$$

\section{REFERENCES}

1. World Health Organization. WHO Director-General's statement on IHR Emergency Committee on novel coronavirus (2019nCoV); 2020 Jan 30 [cited 2020 Feb 8]. Available from: https:// www.who.int/dg/speeches/detail/who-director-general-sstatement-on-ihr-emergency-committee-on-novel-coronavirus-(2019-nCoV).

2. Thomson Reuters. China says virus ability to spread getting stronger; 2020 Jan 26 [cited 2020 Feb 8]. Available from: https:// www.usnews.com/news/world/articles/2020-01-26/chinasays-viruss-ability-to-spread-getting-stronger. 
3. Halasz S. Coronavirus patient in Germany is a 33-year-old German citizen. CNN; 2020 Jan 28 [cited 2020 Feb 8]. Available from: https://edition.cnn.com/asia/live-news/coronavirusoutbreak-01-28-20-intl-hnk/h_0318fbc1b8a46f95e59a30ea0 34000c7.

4. Rothe C, Schunk M, Sothmann P, Bretzel G, Froeschl G, Wallrauch C, et al. Transmission of 2019-nCoV infection from an asymptomatic contact in Germany. N Engl J Med 2020;382(10):970971.

5. Samerski S. Individuals on alert: digital epidemiology and the individualization of surveillance. Life Sci Soc Policy 2018; 14(1):13.

6. Kupferschmidt K. Study claiming new coronavirus can be transmitted by people without symptoms was flawed. Ameri- can Association for the Advancement of Science; 2020 Feb 3 [cited 2020 Feb 8]. Available from: https://www.sciencemag. org/news/2020/02/paper-non-symptomatic-patient-transmitting-coronavirus-wrong.

7. Youn S. Novel coronavirus infection is not a serious disease. Korea JoongAng Daily; 2020 Feb 7 [cited 2020 Feb 8]. Available from: https://news.joins.com/article/23700728 (Korean).

8. Bassetti M, Vena A, Giacobbe DR. The novel Chinese coronavirus (2019-nCoV) infections: challenges for fighting the storm. Eur J Clin Invest 2020;50(3):e13209.

9. Korea Centers for Disease Control and Prevention. Manual of 2019-nCoV infection (5th ed); 2020 Feb 9 [cited 2020 Feb 17]. Available from: https://www.cdc.go.kr/board/board.es?mid= a20507020000\&bid =0019 (Korean). 